\title{
REPERCUSSÃO GERAL: O PROCESSO COLETIVO NO ESTADO DEMOCRÁTICO DE DIREITO
}

General repercussion: the collective process in the democratic state of law

\section{Gabriela Oliveira Freitas}

Mestranda em Direito Processual pela PUC - Minas. Especialista em Direito Processual pela PUC - Minas. Bacharela em Direito pela PUC - Minas. Professora na Faculdade de Santa Luzia - FACSAL. Assessora Judiciária do Tribunal de Justiça de Minas Gerais - TJMG. E-mail: freitasgaby@hotmail.com

RECEBIDO EM: 28.08.12

APROVADO EM: 07.01.13

\section{RESUMO}

Pretende-se pelo presente estudo uma análise acerca do instituto recentemente inserido no Direito Processual Brasileiro, pela Emenda Constitucional $n^{0} 45 / 2003$, a Repercussão Geral, não só como pressuposto de admissibilidade do recurso extraordinário, mas como instituto destinado à tutela de direitos coletivos, no Estado Democrático de Direito. Serão trazidas à análise teorias contrapostas referentes ao processo coletivo, tais como a adotada no sistema de common law, o modelo representativo adotado pela legislação brasileira e o modelo participativo, apresentando diferentes posicionamentos acerca do assunto em estudo, contribuindo para a elucidação do problema. Assim, será analisado o referido instituto, buscando sua adequação ao modelo constitucional do processo. Para o presente estudo, utilizar-se-á a pesquisa bibliográfica e o método dedutivo, partindo-se de uma perspectiva macro para uma concepção micro analítica acerca do tema ora em estudo e, por fim, como procedimento técnico a análise temática, teórica e interpretativa, buscando sugestão para a solução da questão destacada. 
Palavras-chave: Repercussão geral. Recursos repetitivos. Estado Democrático de Direito. Processo coletivo. Ações coletivas. Ações temáticas. Direitos difusos. Direitos coletivos. Direitos individuais Homogêneos. Processo constitucional.

\section{Abstract}

It is intended by this study an analysis about the institutes recently entered the Brazilian procedural law, by the constitutional amendment $n^{\circ} 45 / 2003$, the general repercussion, not only as a assumption of admissibility of extraordinary resource, but also as institute for the protection of collective rights, in the Democrate State of Law. Analysis will be brought to opposing theories concerning the collective process such as that adopted in the common law system, the representative model adopted by the Brazilian legislation and the participatory model, presenting various points of view on the subject under study, contributing to the elucidation of the problem. Then, the above will be analyzed, looking for their adequacy to the constitutional process. For this study, it will use the literature review and the deductive method, starting from a macro perspective to design a micro-analytical about the topic now under study and, finally, as a technical subject analysis, theoretical and interpretive seeking suggestions for resolving the outstanding issue.

Keywords: General repercussion. Resources repetitive. Democrate State of Law. Process collective. Class action. Action themes. Diffuse Rights. Collective Rights. Individual Rights homogeneous. Constitutional PROCESs.

SumáRIo: Introdução. 1. Breves considerações acerca da repercussão geral. 2. Direito processual coletivo. 2.1 Os modelos da common law. 2.2 Os modelos da civil law. $2.3 \mathrm{O}$ modelo participativo do processo coletivo. 3. Repercussão geral como instituto do processo coletivo. Conclusão. Referência.

\section{INTRODUÇÃO}

Diante de uma atual tendência de busca pela celeridade processual, o Direito Brasileiro vem sofrendo uma série de reformas e alterações, visando abreviar o tempo de duração dos procedimentos e combater a tão falada morosidade do Judiciário e denominada "Crise do Supremo Tribunal Federal". 
Uma das recentes alterações, que constitui objeto do presente estudo, refere-se à inclusão no texto da Constituição da República, pela Emenda Constitucional $n^{\circ} 45 / 03$, da Repercussão Geral, posteriormente regulamentada pela Lei 11.418/2006, como pressuposto de admissibilidade do recurso extraordinário, pretendendo não somente limitar os feitos que são remetidos ao Supremo Tribunal Federal, como também promover um julgamento simplificado de feitos com controvérsias consideradas idênticas.

Diante da análise do referido instituto, seu conceito e procedimento previsto na legislação regulamentadora, pretende-se demonstrar que o reconhecimento da repercussão geral implica, por conseqüência, no reconhecimento do caráter coletivo da matéria debatida no Recurso Extraordinário, motivo por que merece ser estudado sob a ótica do processo coletivo.

Pretende-se, ainda, uma breve na álise acerca do processo coletivo e seus modelos adotados nos países de common law e civil law, bem como aproximar o processo coletivo da teoria constitucionalista do processo, adequando-o ao Estado Democrático de Direito.

Tem-se, portanto, que o objetivo do presente trabalho é abordar o instituto da repercussão geral diante do Estado Democrático de Direito, principalmente no que se refere ao processo coletivo, visando demonstrar a inadequação de tratamento do processo coletivo que obsta a concretização da democracia.

\section{BREVES CONSIDERAÇõeS ACERCA DA REPERCUSSÃo GERAL}

Com a promulgação da Emenda Constitucional no 45/2004, a intitulada "Reforma Constitucional do Judiciário", inseriu-se no ordenamento jurídico o instituto denominado Repercussão Geral, como pressuposto intrínseco de admissibilidade do Recurso Extraordinário, consistindo na aplicação de critérios políticos no juízo de admissibilidade do recurso extraordinário.

Acerca da definição de repercussão geral, é informação contida no endereço eletrônico do Supremo Tribunal Federal (www.stf.jus.br):

A Repercussão Geral é um instrumento processual inserido na Constituição Federal de 1988, por meio da Emenda Constitucional 45, conhecida como a "Reforma do Judiciário". O objetivo desta ferramenta é possibilitar que o Supremo Tribunal Federal selecione os Recursos Extraordinários que irá analisar, de acordo com critérios de relevância jurídica, política, social ou econômica. O uso desse filtro recursal resulta numa diminuição do número de processos encaminhados à Suprema Corte. Uma vez constatada a existência de repercussão geral, o STF analisa o mérito da questão e a decisão proveniente dessa análise será aplicada posteriormente pelas instâncias inferiores, em casos idênticos. 
Assim, dispõe o art. 102, $\S 3^{\circ}$, da CR/88, incluído pela EC 45/2004:

No recurso extraordinário o recorrente deverá demonstrar a repercussão geral das questões constitucionais discutidas no caso, nos termos da lei, a fim de que o Tribunal examine a admissão do recurso, somente podendo recusá-lo pela manifestação de dois terços de seus membros.

Entende-se, portanto, que a Repercussão Geral consiste em pressuposto de admissibilidade do Recurso Extraordinário, que visa limitar os recursos que são remetidos ao $\mathrm{STF}$ àqueles que sejam considerados relevantes sob o ponto de vista político, social, jurídico ou econômico, e criando uma forma de julgamento por amostragem.

O ora analisado instituto assemelha-se à anterior argüição de relevância ${ }^{456}$, quer era "verdadeiro processo de triagem", pela verificação da relevância da questão federal por critério claramente discricionário, "do ponto de vista do interesse público - pela repercussão, pelo número de casos, pelas conseqüências amplas”. Assim, tem-se que tanto na repercussão geral quanto na argüição de relevância, a "questão relevante federal transcende ao próprio conflito de interesse envolvido na lide".

A inserção do referido instituto decorre da atual tendência de reformas processuais, visando tornar cada vez mais célere os procedimentos, nos termos do inciso LXXIII, do art. $5^{\circ}$, da CR/88, também inserido pela EC 45/2003 ${ }^{457}$, bem como a superação da já mencionada Crise do $\mathrm{STF}^{458}$, visando diminuir o volume de feitos que são remetidos e julgados nos tribunais superiores.

Visando regulamentar o referido instituto, conforme exigiu o texto constitucional, foi promulgada a Lei 11.418, em 19 de dezembro, que acresceu

\footnotetext{
${ }^{456}$ A argüição de relevância, prevista no art. 119, a e d, Constituição de 1967 e nos arts. 325, I a XI e $327, \$ 1^{\circ}$, do Regimento Interno do STF, exigia que a questão levada a debate no Supremo Tribunal Federal versasse sobre matéria de interesse público. Tal pressuposto de admissibilidade não foi recepcionado pela Constituição de 1988. Segundo Bruno Dantas, a argüição de relevância "se prestava a catalisar o ponto de vista da Corte sobre a sua própria função recursal extraordinária e sobre os grandes temas que mereceriam apreciação da Corte e razão da contribuição que sua decisão daria para o desenvolvimento do sistema positivo e para o aperfeiçoamento das instituições" (Repercussão Geral: Perspectiva histórica, dogmática e de direito comparado: Questões Processuais. São Paulo: Revista dos Tribunais, 2008. p. 257).

457 "LXXIII - a todos no âmbito judicial e administrativo, são assegurados a razoável duração do processo e os meios que garantam a celeridade de sua tramitação."

${ }^{458}$ A chamada "Crise do Supremo Tribunal Federal" refere-se ao excesso de julgamentos realizados pelo STF e ampliação de sua competência, conforme leciona José Alfredo de Oliveira Baracho, na obra Direito Processual Constitucional (Belo Horizonte: Fórum, 2008), afirmando que tal debate não é recente, tendo sido a questão abordada pelo Professor Noé Azevedo, em tese apresentada no Congresso Jurídico Nacional de 1943, referindo-se à "avalanche de recursos" e propondo a "descentralização do serviço judiciário";
} 
ao Código de Processo Civil os arts. 543-A e B, dispondo acerca do procedimento para reconhecimento da repercussão geral.

$\mathrm{O}$ art. 543-A, $\S 1^{\circ}$, do $\mathrm{CPC}$, define o conceito de repercussão geral, determinando que esta ocorre quando a controvérsia abranger "questões relevantes do ponto de vista econômico, político, social ou jurídico, que ultrapassem os interesses subjetivos da causa", sendo também transcendente, ou seja, deve ultrapassar o âmbito de interesse das partes.

Art. 543-A. O Supremo Tribunal Federal, em decisão irrecorrível, não conhecerá do recurso extraordinário, quando a questão constitucional nele versada não oferecer repercussão geral, nos termos deste artigo.

$\S 1^{\circ}$ Para efeito da repercussão geral, será considerada a existência, ou não, de questões relevantes do ponto de vista econômico, político, social ou jurídico, que ultrapassem os interesses subjetivos da causa.

Pelo supracitado dispositivo legal, tem-se que o reconhecimento da repercussão geral depende da apreciação de conceitos indeterminados, ou seja, deve-se verificar se a questão é relevante no âmbito econômico, político, social ou jurídico, assim, "abre-se ao aplicador da norma, como é intuitivo, certa margem de liberdade. Algo de subjetivo quase sempre haverá nessa operação concretizadora, sobretudo quando ela envolva, conforme com freqüência, a formulação de juízo de valor" (CASAGRANDE, 2008, p. 115).

Em assim sendo, acerca do reconhecimento da repercussão geral, é ensinamento de Heloísa Monteiro Esteves:

De acordo com a Lei 11.418/2006, existirão dois critérios para se aferir a repercussão geral, a saber: o critério objetivo, denominado, pelo Supremo, de presunção de repercussão geral, segundo o qual haverá repercussão geral sempre que o recurso impugnar decisão contrária a súmula ou jurisprudência dominante do Supremo Tribunal Federal e o critério subjetivo que considera presente a repercussão geral sempre que existir questão relevante do ponto de vista econômico, político, social ou jurídico e que transcenda os interesses subjetivos da causa (ESTEVES, 2010, p. 185).

É também o ensinamento de Luiz Guilherme Marinoni e Daniel Mitidiero, na obra "Repercussão Geral no Recurso Extraordinário":

A fim de caracterizar a existência de repercussão geral e, destarte, viabilizar o conhecimento do recurso extraordinário, nosso legislador 
alçou mão de uma fórmula que conjuga relevância e transcendência (repercussão geral $=$ relevância + transcendência $)$. [...]

E prossegue:

Impõe-se que a questão debatida, além de ensartar como de relevante importe econômico, social, político ou jurídico, ultrapasse o âmbito de interesse das partes. Vale dizer: tem de ser transcendente. Também aqui o legislador infraconstitucional alça mão de linguagem propositadamente vaga, consentindo ao Supremo Tribunal Federal a aferição de transcendência da questão debatida a partir do caso concreto. A transcendência da controvérsia constitucional levada ao conhecimento do Supremo Tribunal Federal pode ser caracterizada tanto em uma perspectiva qualitativa como quantitativa. Na primeira, sobreleva para individualização da transcendência o importe da questão debatida para a sistematização e desenvolvimento do direito. Na segunda, o número de pessoas susceptíveis de alcance, atual ou futuro, pela decisão daquela questão pelo Supremo e, bem assim, a natureza do direito posto em causa (notadamente, coletivo ou difuso). (MARINONI, MITIDIERO, 2007, pp. 33-37).

Assim, merece crítica tal critério estabelecido na legislação para verificar a existência de repercussão geral, vez que confere discricionariedade aos julgadores, permitindo que seja aferida a transcendência de uma questão a partir de critérios subjetivos ${ }^{459}$.

Ressalte-se também que o reconhecimento da inexistência de repercussão geral, que depende da votação de pelo menos oito ministros do STF, implica no indeferimento liminar de todos os outros recursos extraordinários sobre a mesma matéria, assim como o reconhecimento da presença de tal pressuposto acarreta a vinculação de tais recursos à decisão de mérito proferida, nos termos do art. 543-B, $\S 5^{\circ}$, do CPC.

Sobre tal questão, é o entendimento esposado por Fabrício Santos Almeida, na dissertação intitulada "Repercussão Geral: uma análise crítica das suas implicações no processo penal democrático", apresentada ao curso de Pós Graduação Stricto Senso em Direito Processual da Pontifícia Universidade Católica de Minas Gerais:

\footnotetext{
${ }^{459}$ Nesse sentido, denuncia Lênio Streck que "a Constituição, que deveria ser o lócus privilegiado para a obtenção de respostas concretizadoras, foi, ela mesma, transformada em texto aberto, por vezes, pan-principiologista". (STRECK, Luiz Lenio. Hermenêutica, Constituição e Processo, ou de "como discricionariedade não combina com democracia": O Contraponto da Resposta Correta. In: CATTONI DE OLIVEIRA, Marcelo Andrade; MACHADO, Felipe Daniel Amorim (Coords.). Constituição e Processo. Belo Horizonte: Del Rey, 2009. p. 7).
} 
A decisão negativa do STF quanto à configuração da repercussão geral vincula todos os outros tribunais do país, inclusive o próprio STF. Portanto, reconhecendo o STF que não há repercussão na matéria apresentada no recurso, tal decisão transcende o caso, podendo ser base para o não conhecimento de outros recursos extraordinários, que tratam da mesma questão constitucional (ALMEIDA, 2009, p. 61).

No presente estudo, interessa também a redação dada ao art. 543-B, que versa acerca da multiplicidade de recursos extraordinários fundados na mesma questão controvertida, hipótese em que o julgamento do recurso escolhido como representativo servirá de parâmetro para o julgamento dos demais.

Art. 543-B Quando houver multiplicidade de recursos com fundamento em idêntica controvérsia, a análise da repercussão geral será processada nos termos do Regimento Interno do Supremo Tribunal Federal, observado o disposto neste artigo.

Assim, o art. 543-B estabelece competência ao Tribunal de origem para selecionar um ou mais recursos que represente adequadamente a controvérsia, para que sejam encaminhados ao STF, que servirão de paradigma para todos os demais recursos, que ficarão suspensos, aguardando o STF se pronunciar sobre a existência ou não de repercussão geral na tese defendida no recurso paradigma e, posteriormente, acerca do mérito do recurso.

Verifica-se, portanto, que para aferir a existência ou não da repercussão geral, o STF, diante de sua competência exclusiva, pode adotar dois procedimentos, quais sejam, aquele para o recurso extraordinário isolado, cuja matéria nele discutida não é repetida em outros feitos, apesar de a decisão transcender o interesse das partes, e um segundo procedimento para recursos extraordinários em multiplicidade, cuja matéria então debatida também se encontra presente em outros recursos, os denominados recursos por amostragem.

Desse modo, com a regulamentação da repercussão geral pela Lei 11.418/2006, criou-se não somente um requisito de admissibilidade para o Recurso Extraordinário, mas também uma forma de julgamento simplificado dos recursos repetitivos, com vinculação dos demais tribunais às decisões proferidas pelo Supremo Tribunal Federal, passando o Recurso Extraordinário a assumir a "função de defesa da ordem constitucional objetiva" (DANTAS, 2008, p. 74).

Resta, portanto, induvidoso que tal instituto implica no reconhecimento do caráter coletivo da questão debatida no Recurso Extraordinário, motivo por que se revela a importância do estudo deste pressuposto de admissibilidade na perspectiva das ações coletivas. 
Sobre tal questão, é o entendimento doutrinário:

[...] o sistema jurídico aposta em "precedentes vinculativos" para a resolução do problema decorrente do crescimento das demandas pela concretização dos direitos perante o Poder Judiciário (e a jurisdição constitucional). Mas, quanto mais realidade, mais ficção. Quanto mais demandas e processos, mais mecanismos restritivos. Dito de outro modo, quanto mais "coisas”, mais "conceitualizações” (STRECK, 2009, p. 15).

Desse modo, após tais considerações breves acerca do instituto da repercussão geral, pretende-se uma análise acerca do direito processual coletivo e suas peculiaridades, visando a compreensão do estudado pressuposto de admissibilidade como um instituto destinado à tutela de direitos que extrapolam a esfera individual, atingindo a coletividade.

\section{Direito Processual Coletivo}

Para que seja possível a compreensão da repercussão geral como instituto destinado à tutela de direitos coletivos, necessário esclarecer que se entende por Processo Coletivo aquele que visa tutelar os direitos coletivos, dentre os quais se tem os coletivos em sentido estrito e os difusos e ainda os individuais homogêneos, sendo necessário, portanto, defini-los para uma melhor compreensão do tema proposto.

Ressalte-se, também, que incorreta a expressão "interesses coletivos", tendo em vista que, conforme entendimento esposado por Vicente de Paula Maciel Junior, o interesse, entendido como manifestação de vontade em face de um bem, "é sempre individual, porque pertence à esfera psíquica que liga um sujeito a um bem" (MACIEL JUNIOR, 2006, p. 54).

Desse modo, tendo em vista o supramencionado conceito de interesse, como algo existente somente na esfera individual, inviável falar em interesses na esfera coletiva, revelando-se mais correta a adoção das expressões direitos difusos, coletivos ou individuais homogêneos.

Assim, prosseguindo no estudo sobre a tutela dos direitos difusos, coletivos e individuais homogêneos, abordar-se-á os modelos processuais coletivos: da common Law, da civil Law e o modelo participativo.

\subsection{OS MODELOS DA COMMON LAW}

Nos países de common law, tais como Estados Unidos, Canadá e Austrália, adota-se a class action como sistema adequado para a tutela de 
direitos coletivos, "exigindo-se um número bastante elevado de pessoas que possa vir a se beneficiar da ação coletiva, para permitir ao juiz se convencer de que seja a forma mais adequada, ao invés de uma forma individual." (AFONSO, 2010, p. 303).

Apesar de ter tido grande influência na positivação do direito processual coletivo brasileiro, as class actions possuem características diversas, principalmente no tocante à legitimação para agir e à coisa julgada.

Sobre as class actions, leciona Vicente de Paula Maciel Junior:

Nesse sistema há um alargamento do juízo para a discussão de um problema referente a uma classe ou categoria de pessoas. Aquele que propõe a ação (chamado de class actor) não precisa de prévia autorização através de lei específica. Normalmente é uma associação que se apresenta em juízo como representante de uma classe. $\mathrm{O}$ ressarcimento do dano não fica limitado ao indivíduo prejudicado, alcançando toda a extensão do ato violador. $\mathrm{O}$ juiz deve exercer um importante papel de controle da admissibilidade da representação. (MACIEL JUNIOR, 2006, pp. 139-140).

\section{É também lição de Suzana Rocha Savoi Diniz:}

Salienta-se, portanto, que a class action é uma ação representativa representative action, em que o autor representa em juízo os interesses dos demais membros - ausentes - do grupo. Este representante propõe a ação coletiva em nome próprio e em nome de todos os demais que se enquadram em uma situação semelhante à sua, o que gera dois pedidos independentes: o pedido individual, em benefício do representante, e o pedido coletivo, em benefício do grupo. (DINIZ, 2008, p. 123).

No sistema em questão, cabe ao magistrado apreciar a adequação da representatividade, inexistindo limites legais para definir quem seria o representante adequado para atuar em juízo, com legitimação extraordinária, na busca pela tutela dos direitos coletivos.

Destaque também para a Regra 23 das Federal Rules of Civil Procedure, que aborda uma série de questões e exigências para que a demanda seja tratada como uma ação coletiva, tais como controle da representatividade, identificação da classe, objeto da demanda, eficácia do provimento jurisdicional, assistência técnica, tratando também dos pressupostos para seu regular prosseguimento.

No que se refere à legitimação para agir, no modelo das class actions, necessário que o representante considerado adequado integre à classe interessada na demanda, devendo estar claramente definida, de modo a permitir 
o "alcance e os limites subjetivos do julgado, embora não se exija, a priori, desde o limiar do processo, a indicação exata das pessoas ou mesmo do número certo de interessados" (MENDES, 2002, p. 74).

Ressalte-se que, para que se entenda cabível e adequada a ação coletiva, necessário apreciar o "binômio da prevalência das questões comuns sobre as individuais e da superioridade da ação coletiva em relação a individual" (AFONSO, 2010, p. 304). Necessário, ainda, sejam notificados dos interessados para que exerçam o direito à regra do opt-out, ou seja, é possível que os interessados optem por não se submeterem aos efeitos da sentença.

\subsection{OS MODELOS DA CIVIL LAW}

O modelo adotado pela legislação brasileira, conforme previsto na Lei de Ação Civil Pública e no Código de Defesa do Consumidor, também prevê o sistema representativo, com grande influência das class actions, porém com a representatividade definida por lei.

A Lei de Ação Civil Pública prevê em seu art. 5, quem são os representantes adequados, elencando-os em rol taxativo (Ministério Público, Defensoria Pública, União, Estados, Distrito Federal, Municípios, autarquia, empresa pública, fundação, sociedade de economia mista e associações, constituídas há mais de um ano e tenha por finalidade a proteção ao meio ambiente, ao consumidor, à ordem econômica, à livre concorrência ou ao patrimônio artístico, estético, histórico, turístico e paisagístico).

Desse modo, tem-se que, no sistema brasileiro, a representação adequada é definida pela legislação; ao contrário do sistema norte-americano, no qual cabe ao magistrado apreciar a adequação da representatividade.

Sobre a legitimação para propositura de ações coletivas no direito brasileiro, leciona Hugo Nigro Mazzilli:

Em se tratando de defesa de interesses individuais homogêneos ou interesses coletivos, o lesado, individualmente considerado, não poderá ser autor de pedido coletivo: só poderá, por legitimação ordinária, pedir a defesa de seu próprio interesse em ação individual, quer nesta compareça sozinho ou em litisconsórcio com outros lesados individuais. Mas, em ação civil pública ou coletiva já regularmente ajuizada por um dos co-legitimados do art. $5^{\circ}$ da LACP ou do art. 82 do CDC, o indivíduo que compartilhe lesão individual homogênea ou coletiva apenas pode habilitar-se como assistente litisconsorcial, desde que, tendo processo individual em andamento, a tempo tenha requerido sua suspensão. (MAZZILLI, 2005, p. 301). 
Sobre a mesma questão, ensina Pedro Lenza que:

[...] o representante adequado da coletividade age em nome próprio e, pouco importando se, também, na defesa de seus interesses institucionais, necessariamente, na defesa de um direito alheio, de uma coletividade, mais ou menos organizada, substituindo-a. (LENZA, 2005, p. 191).

Em assim sendo, no sistema representativo adotado pelo direito brasileiro, somente os representantes adequados, com autorização legal, podem propor e participar da ação coletiva, sem a participação direta dos interessados, que serão diretamente afetados pela decisão proferida.

\subsection{O MODELO PARTICIPATIVO DO PROCESSO COLETIVO}

Vicente de Paula Maciel Junior apresenta, em sua obra "Teoria das Ações Coletivas: As ações coletivas como ações temáticas", visão diversa acerca do Direito Processual Coletivo, apresentando uma proposta de estudo das ações coletivas como ações temáticas, resgatando aos interessados difusos a "legitimação que lhes foi roubada pelo modelo de processo coletivo centrado no individualismo" (MACIEL JUNIOR, 2006, p. 189).

Desse modo, em contraposição com o modelo representativo adotado pelo legislador brasileiro, o foco na ação coletiva deveria ser o objeto, e não o sujeito, por isso a denominação de "ações temáticas", permitindo uma ampla e irrestrita participação dos interessados, necessária para a construção do provimento no Estado Democrático de Direito, e passando a abordar as ações coletivas como ações temáticas, definindo a participação a partir da delimitação do tema debatido.

Vale ressaltar que tal modelo apresenta maior conformidade com as diretrizes do Estado Democrático de Direito ${ }^{460}$ e com o modelo constitucional do processo $^{461}$, permitindo a formação participada do mérito do provimento jurisdicional, diante da legitimação de todos os interessados difusos.

\footnotetext{
${ }^{460}$ Entende-se por Estado Democrático de Direito, conforme lição de Ronaldo Brêtas de Carvalho Dias, na obra "Processo Constitucional e Estado Democrático de Direito", como a junção do princípio democrático ao princípio do Estado de Direito, limitando a atuação do Estado pelo direito positivado e reconhecendo a legitimidade do exercício do poder pela democracia, ou seja, pela sua origem no povo.

${ }^{461}$ A expressão "modelo constitucional do processo" foi cunhada por Italo Andolina e Giuseppe Vignera, no prosseguimento dos estudos da teoria constitucionalista do processo, que teve como pioneiro Hector Fix-Zamudio, sustentada, nos termos dos ensinamentos de Rosemiro Pereira Leal, a partir do entendimento do "processo como instituição constitucionalizada apta a reger, em contraditório, ampla defesa e isonomia, o procedimento, como direito-garantia fundamental" (LEAL, 2010, p. 84).
} 
Leciona Flaviane de Magalhães Barros Pelegrinni que "para se definir que serão as partes em um processo, em concreto, deve-se analisar o provimento jurisdicional requerido e os sujeitos que serão afetados pelo respectivo provimento" (PELEGRINNI, 2003).

No Estado Democrático de Direito, inviável, mesmo no âmbito do processo coletivo, limitar a garantia fundamental do devido processo legal, que abrange a ampla defesa, o exercício do contraditório, a isonomia, o direito ao advogado e a devida fundamentação das decisões judiciais.

Sobre tal questão, afirma Ronaldo Brêtas de Carvalho Dias, que o devido processo legal:

[...] deve ser entendido como um bloco aglutinante e compacto de diversos direitos e garantias fundamentais inafastáveis ostentados pelas pessoas do povo (partes, quando deduzem pretensão à tutela jurídica nos processos perante os órgãos jurisdicionais: a) direito de amplo acesso à jurisdição, prestada dentro de um tempo útil ou lapso temporal razoável; b) garantia do juízo natural; c) garantia do contraditório; d) garantia da ampla defesa, com todos os meios e recursos a ela (defesa) inerentes, aí incluído o direito à presença do advogado ou de defensor público; e) garantia da fundamentação racional das decisões jurisdicionais, com base no ordenamento jurídico vigente (reserva legal); f) garantia de um processo sem dilações indevidas. (BRÊTAS, 2010, p. 125)

Portanto, o devido processo legal é meio de conter as arbitrariedades nas decisões jurisdicionais, e permitir a participação igualitária das partes na formação dos provimentos, ressalvando que a observância de direito não se limita ao âmbito jurisdicional, abrangendo também os processos legislativos e administrativos e as relações entre particulares.

Assim, no Processo Coletivo, "a legitimação do provimento decorrente de uma ação coletiva se dá pelo procedimento que permita a inclusão dos legitimados para a participação na construção da decisão" (MACIEL JUNIOR, 2006, p. 178), em observância ao devido processo legal e ao modelo constitucional do processo.

\section{REPERCUSSÃo GERAL COMO INSTITUTO DO PROCESSO COLETIVO}

Diante de tais considerações, resta induvidoso que o julgamento dos recursos pela escolha de representativos, como ocorre na repercussão geral, trata-se de forma de processo coletivo, tendo em vista que ocorre, em um único julgamento, a discussão acerca de matéria de direito coletivo, cujo provimento valerá para os demais recursos. 
O caráter coletivo do referido instituto também se evidencia diante da necessidade de que os recursos extraordinários versem sobre matérias que ultrapassem o âmbito do interesse individual, o que ocorre pela verificação da presença do denominado instituto da "transcendência".

Induvidosa a necessidade de limitar as matérias debatidas pelo Supremo Tribunal Federal, em razão do excesso de feitos e da impossibilidade de devida apreciação destes no tempo devido, conforme é ensinamento de Ronaldo Brêtas de Carvalho Dias e André Soares:

A repercussão geral veio no sentido de possibilitar a diminuição dos recursos que estavam sendo apresentados junto ao STF. Como este Tribunal possui funções políticas e jurídicas, não poderia mais ficar decidindo questões apenas inter partes. Era necessário que as decisões do Supremo Tribunal Federal tivessem uma ampla repercussão para toda a sociedade e não somente para um dado caso concreto. Assim, a repercussão geral é justamente um instrumento destinado a impedir a interposição de recursos extraordinários, bem como um mecanismo que possibilita maior efetividade das decisões do Supremo. (BRÊTAS, SOARES, 2011, p. 482).

Sobre a mesma questão, leciona Alexandre Gustavo Melo Franco Bahia:

Argumenta-se correntemente que os Tribunais Superiores estão sobrecarregados de processos (como, em geral, todo o Judiciário), o que praticamente os inviabilizaria de exercer aquelas "altas funções" mencionadas. Assim, "como sua atividade seria tão diversa daquelas dos demais Tribunais, deveriam contar também com tratamento diferenciado, tal qual outras Cortes Superiores no mundo" - particularmente a Suprema Corte americana que, tendo o poder de escolher discricionariamente as causas a julgar, teria condições de proferir melhores decisões.

Por essas razões vêm surgindo ao longo dos anos vários meios de criar barreiras de acesso àqueles Tribunais a fim de que ficassem incumbidos apenas das "grandes questões", que transcenderiam o "mero" interesse dos litigantes. (BAHIA, 2009, p. 365).

Assim, conforme entendimento de Lênio Streck, ocorre um retrocesso, "pelo qual se procura estabelecer uma regra, geral e universalizante, que permita um julgamento massivo de todos os processos pressupostos como iguais", ignorando que os recursos "representam causas e não apenas teses jurídicas abstratas” (STRECK, 2009, p. 9). 
Destaque-se, ainda, que o reconhecimento de repercussão geral impede o conhecimento de demais recursos extraordinários e vincula o entendimento do STF ao dos tribunais estaduais e regionais, o que torna claro que toda matéria debatida no STF, tendo sido reconhecida sua repercussão além dos limites dos interesses individuais das partes litigantes, refere-se à matéria de direito coletivo, devendo ser tratada, portanto, como tal, observados os direitos e garantias fundamentais inerentes ao Estado Democrático de Direito.

No entanto, a regulamentação do referido instituto pela Lei 11.418/2006 não cuidou de abordar o procedimento observando as normas do direito processual coletivo. Assim, inviável conceder a qualquer recorrente o poder de representação dos demais interessados, sem que, nos termos da atual legislação processual, este possua legitimidade, bem como inviável restringir a participação dos interessados na construção do provimento jurisdicional.

Ademais, considerando o processo coletivo no Estado Democrático de Direito e o modelo participativo do processo coletivo, verifica-se que o instituto da repercussão geral, conforme regulamentado, limita e impede o debate dos interessados, culminando em um provimento jurisdicional decorrente somente do entendimento do magistrado, desconsiderando a participação das partes, o que o torna ilegítimo.

Constata-se, portanto, que tem ocorrido uma grande preocupação com a celeridade processual, com visível prejuízo dos direitos fundamentais.

É a lição de Aroldo Plínio Gonçalves:

A preocupação com o rápido andamento do processo, com a superação do estigma da morosidade da Justiça que prejudica o próprio direito de acesso ao Judiciário, porque esse direito é também o direito à resposta do Estado ao jurisdicionado, é compartilhada hoje por toda a doutrina do Direito Processual Civil. As propostas de novas categorias e de novas vias que abreviem o momento da decisão são particularmente voltadas para a economia e a celeridade como predicados essenciais da decisão justa, sobretudo quando a natureza dos interesses em jogo exige que os ritos sejam simplificados. Contudo, a economia e a celeridade não são incompatíveis com as garantias das partes, e a garantia constitucional do contraditório não permite que seja ele violado em nome do rápido andamento do processo. (GONÇALVES, 2001, pp. 124-125).

Tem-se, portanto, que não basta buscar um processo célere para que o processo seja efetivo, exige-se também a observância das garantias processuais fundamentais.

Em assim sendo, o provimento proferido no julgamento de feitos com repercussão geral é inválido, pela ausência de ampla participação das partes em sua construção, conforme ensina Dierle José Nunes: 
Assim, em decorrência da conjugação das garantias constitucionais do contraditório e da defesa, cria-se uma impossibilidade de atuação monológica do juiz na construção de todos os provimentos, pois estes seriam inválidos toda vez que levassem em consideração aspectos fáticos e jurídicos não debatidos e problematizados com as partes.

Cria-se, então, obrigatoriamente, uma estrutura procedimental intersubjetiva e comparticipativa de formação de todos os provimentos judiciais (NUNES, 2006, p. 151).

Nesse sentido, é o ensinamento de Dierle José Nunes, Humberto Theodoro e Alexandre Bahia:

[...] o Tribunal Superior ao criar uma tese com base em alguns casos 'pinçados'(como veremos), rejulgaria tão-somente estes, desprezando os argumentos dos demais recursos e dos 'interessados não participantes', algo que exige uma releitura de aplicação (NUNES, THEODORO JUNIOR, BAHIA, 2009, p. 19).

Também é o entendimento de Fabrício dos Santos de Almeida:

Assim, com base em uma escolha discricionária (conceito jurídico indeterminado), o STF seleciona o que pretende julgar. Da mesma forma arbitrária, não permite a participação dos afetados, pois os Ministros, por exemplo, nos casos de recursos múltiplos, julgam um processo que terá efeito a todos os outros que tratem de "idêntica" controvérsia.

Por fim, se respeitada fosse a engrenagem de complementaridade das dimensões da autonomia jurídica (pública e privada), na perspectiva procedimental, terminaria por retirar dos ombros do juiz e das partes o ônus de encontrarem, de forma solipsista, a melhor aplicação do Direito (ALMEIDA, 2009, p. 80).

E prossegue:

Inevitável, portanto, diante de uma concepção procedimental do Estado Democrático de Direito, perceber que a repercussão geral, na verdade, retira a possibilidade de discussão de questão constitucional no último espaço argumentativo possível para implementação discursiva dessa discussão, qual seja, o recurso extraordinário (ALMEIDA, 2009, p. 81). 
Tem-se, portanto, que necessária a ampliação do debate acerca das questões de direito coletivo, em sede de Repercussão Geral, conforme propõe Vicente de Paula Maciel Junior, que afirma que "quanto maior a participação dos interessados na formação do mérito maior será a possibilidade de que esse processo represente o conflito coletivo de forma ampla" (MACIEL JUNIOR, 2006, p. 179).

E conclui:

As ações coletivas não devem ser rígidas quanto à formação do mérito, porque se o fato abrange um número indeterminado de interessados, é natural que dentre eles existam manifestação de vontades em sentidos diferentes e muitas vezes contraditórios. A ação dos diversos interessados difusos deve conduzir a uma possibilidade de 'ampliação flexível do mérito no processo coletivo'. Se assim não for, corre-se o risco de se transformar a decisão judicial do processo coletivo em uma visão unilateral e representativa apenas de uma parcela dos interessados difusos na questão litigiosa (MACIEL JUNIOR, 2006, p. 180).

Desse modo, o referido modelo participativo revela-se mais adequado ao Estado Democrático de Direito, tendo em vista que o provimento jurisdicional "deverá ser o resultado lógico da atividade procedimental desenvolvida em torno das questões discutidas e dos argumentos produzidos em contraditório pelas partes" (BRÊTAS, 2010, p. 131), construído de forma participada, permitindo que as partes manifestem-se sobre os termos do processo, conforme é lição de Ronaldo Brêtas de Carvalho Dias:

[...] a função jurisdicional somente se concretiza dentro da moderna e inafastável estrutura constitucionalizada do processo e a declaração final do Estado, decorrente do poder de cumprir o dever de prestá-la, quando e se provocado por qualquer um do povo ou mesmo por qualquer órgão estatal, inserida na decisão, sentença ou provimento ali prolatados, jamais será um ato isolado ou onipotente do órgão jurisdicional, ditando ou criando direitos a seu talante, máxime se fundados na fórmula ilógica, inconstitucional e antidemocrática do 'livre (ou prudente) arbítrio' do juiz, mas resultado lógico de uma atividade jurídica realizada com a obrigatória participação em contraditório daqueles interessados que suportarão seus efeitos (BRETÂS, 2004, p. 88).

Desse modo, tem-se que a aplicação da repercussão geral, conforme disposta na legislação regulamentadora, inobserva os direitos e garantias 
fundamentais constitucionais da ampla defesa e do contraditório, os quais "permitem a construção de um procedimento jurisdicional legitimo que possibilita um resgate discursivo das razões de cada decisão judicial, assegurando a correção da falibilidade do processo" (NUNES, 2006, p. 143).

$\mathrm{O}$ que ocorre, em tais julgamentos, é o indevido exercício da atividade jurisdicional, permitindo que os julgadores suprimam toda a participação dos interessados e atuem de forma solipsita e isolada, desconsiderando todo o debate e argumentação produzidos pelas partes interessadas.

Dierle José Coelho Nunes prossegue criticando o julgamento por amostragem também em sua obra "Processo Jurisdicional Democrático":

Não se pode acreditar mais em uma justiça social definida antes do debate processual (tese já julgada), eis que só as peculiaridades do caso concreto (não de uma massa de casos), definidas endoprocessualmente, conseguem permitir, mediante o estabelecimento de um fluxo discursivo entre os interessados e o órgão decisor, a formação de um provimento adequado. (NUNES, 2006, p. 143).

Nesse mesmo sentido, ensina Dierle José Nunes, Humberto Theodoro Junior e Alexandre Bahia, segundo os quais, diante "da existência de um litisconsórcio por afinidade entre os recorrentes, em caso de recursos com fundamento idêntico, a solução não poderia ser tal que violasse as garantias do devido processo constitucional." (NUNES, BAHIA, THEODORO JUNIOR, 2009, p. 38).

Conforme lição de Streck "não se pode olvidar a 'tendência' contemporânea (brasileira) de apostar no protagonismo judicial como uma das formas de concretizar direitos" (STRECK, 2010, p. 20), o que demonstra clara adesão do nosso processo atual à teoria do processo como relação jurídica ${ }^{462}$, de forma incompatível com as diretrizes do Estado Democrático de Direito.

No entanto, não é o protagonismo judicial e, por consequência, decisões solipsistas que concretizam os direitos. Somente é possível falar em concretização de direitos e, por consequência, em adequada tutela dos direitos coletivos, por meio do devido processo constitucional.

\footnotetext{
${ }^{462}$ A teoria do processo como relação jurídica foi desenvolvida por Oskar Von Bullow, em 1868, trazida ao Brasil por Enrico Tulio Liebman, influenciando Alfredo Buzaid na elaboração do Código de Processo Civil de 1973 e disseminando a teoria pela denominada Escola Paulista de Processo, principalmente por Ada Pelegrini Grinover e Cândido Rangel Dinamarco. Segundo Rosemiro Pereira Leal, os teóricos dessa escola instrumentalista "conectaram o Processo à Jurisdição, em escopos metajurídicos, definindo processo como se fosse uma corda a serviço da atividade jurisdicional", que culminaria na "Justiça Redentora para todos os homens, trazendolhes paz e felicidade" (LEAL, 2010, p. 30).
} 
Assim, apesar de correta a intenção e a função da repercussão geral, equivocada sua regulamentação, vez que esta não pode ser aplicada em desconformidade com a disciplina constitucional principiológica (BRÊTAS, 2010, p. 35)

\section{Conclusão}

Diante de tais considerações, inviável que, no Estado Democrático de Direito, admita-se que sejam criados e regulamentados institutos de processo coletivo em desconformidade com o modelo constitucional do processo, como ocorre no caso da Repercussão Geral, o que afasta a legitimidade e validade do provimento proferido nos casos de recursos repetitivos, tendo em vista que não produzido sob a observância do devido processo e sem a efetiva participação das partes interessadas.

Em se tratando de processo coletivo, diante das diretrizes decorrentes do princípio do Estado Democrático de Direito, não cabem limitações à ampla participação das partes interessadas, o que configura clara ofensa aos direitos fundamentais à ampla defesa e contraditório, invalidando, portanto, o provimento obtido.

Desse modo, verifica-se que a repercussão geral, apesar de incorporada ao direito brasileiro sob o argumento de celeridade e efetividade do provimento jurisdicional, bem como no fortalecimento do STF como Corte Constitucional, encontra-se na contra-mão da garantia fundamental do devido processo legal e do modelo constitucional do processo.

Somente é possível considerar que uma sentença proferida em ação coletiva produza efeitos aplicáveis e oponíveis contra todos, caso permita a participação de todos os interessados, observando o devido processo legal, oportunizando, assim, o contraditório e a ampla defesa, garantindo a construção de um provimento participado.

E também só é possível considerar legitimo um provimento jurisdicional quando construído com a participação de todos os seus interessados, como proposto pelo modelo participativo do processo coletivo proposto por Vicente de Paula Maciel Junior, caso em que inviável estabelecer quaisquer limites para a eficácia e os efeitos do provimento jurisdicional.

Conclui-se, desse modo, que a Repercussão Geral, conforme determinação dos arts. 543-B e C, do Código de Processo Civil, encontra-se em total desconformidade com o modelo participativo do processo coletivo, com a disciplina constitucional principiológica e com as diretrizes do Estado Democrático de Direito, e, por via de conseqüência, faz com que o Supremo Tribunal Federal prossiga proferindo decisões totalmente ilegítimas, motivo por que necessária a revisitação deste instituto sob a ótica proposta. 


\section{REFERÊNCIAS}

AFONSO, Fabiano. Liquidação de Sentença Coletiva.Curitiba: Juruá, 2010.

ALMEIDA, Fabrício Santos. Repercussão Geral: uma análise crítica das suas implicações no processo penal democrático. 2009. Dissertação (Mestrado em Direito Processual) - Pontifícia Universidade Católica, Belo Horizonte.

BAHIA, Alexandre Gustavo de Melo Franco. Os recursos extraordinários e a co-originalidade dos interesses públicos e privado no interior do processo: reformas, crises e desafios à jurisdição desde uma compreensão procedimental do Estado Democrático de Direito. In:CATTONI DE OLIVEIRA, Marcelo Andrade; MACHADO, Felipe Daniel Amorim (coords.) Constituição e Processo: A contribuição do Processo ao Constitucionalismo Brasileiro. Belo Horizonte: Del Rey, 2009.

BARACHO, José Alfredo de Oliveira. Direito Processual Constitucional: Aspectos Contemporâneos. Belo Horizonte: Fórum, 2006.

BRÊTAS, Ronaldo de Carvalho Dias. Responsabilidade do Estado pela função jurisdicional. Belo Horizonte: Del Rey, 2004.

BRÊTAS, Ronaldo de Carvalho Dias. Processo Constitucional e o Estado Democrático de Direito. Belo Horizonte: Del Rey, 2010.

CARVALHO FILHO, José dos Santos. Ação Civil Pública: comentários por artigo. Rio de Janeiro: Lumen Juris, 2007.

CASAGRANDE, Érico Vinícius Prado. Repercussão Geral no Recurso Extraordinário e Garantia Fundamental da Ampla Defesa: Estudo do novo requisito de admissibilidade do recurso extraordinário sob a perspectiva de uma teoria do direito democrático. 2008. Dissertação (Mestrado em Direito Processual) - Pontifícia Universidade Católica, Belo Horizonte.

DANTAS, Bruno. Repercussão Geral: perspectivas histórica, dogmática e de direito comparado: questões processuais. São Paulo: RT, 2008.

DINIZ, Suzana Rocha Savoi. A Coisa Julgada no Processo Coletivo na Perspectiva das Ações Temáticas. 2008. Dissertação (Mestrado em Direito Processual) - Pontifícia Universidade Católica, Belo Horizonte. 
ESTEVES, Heloísa Monteiro de Moura. Recursos no Processo Civil. 2. ed. Belo Horizonte: Atualizar, 2010.

GONÇAlVES, Aroldo Plínio. Técnica Processual e Teoria do Processo. Rio de Janeiro: Aide, 2001.

LEAL, Rosemiro Pereira. Teoria geral do processo - Primeiros estudos. Rio de Janeiro: Forense, 2010.

LENZA, Pedro. Teoria Geral da Ação Civil Pública. São Paulo: Revista dos Tribunais, 2005.

MACIEL JUNIOR, Vicente de Paula. Teoria das Ações Coletivas: As ações coletivas como ações temáticas. São Paulo: LTr, 2006.

MARINONI, Luiz Guilherme; MITIDIERO, Daniel. Repercussão Geral no Recurso Extraordinário. São Paulo: Revista dos Tribunais, 2008.

MAZZILLI, Hugo Nigro. A defesa dos interesses difusos em juizo: meio ambiente, consumidor, patrimônio cultural, patrimônio público e outros interesses. 18. ed. São Paulo: Saraiva: 2005.

MENDES, Aluisio Gonçalves de Castro. Ações Coletivas no direito comparado e nacional. São Paulo: Revista dos Tribunais, 2002.

NUNES, Dierle José Coelho. Direito Constitucional ao Recurso: Da Teoria Geral dos Recursos e da Comparticipação nas decisões. Rio de Janeiro: Lumen Juris, 2006.

NUNES, Dierle José Coelho. Processo Jurisdicional Democrático. Curitiba: Juruá, 2011.

PELLEGRINI, Flaviane de Magalhães Barros. O processo, a jurisdição e a ação sob a ótica de Elio Fazzalari. In Virtuajus. Revista Eletrônica da Faculdade Mineira de Direito, Belo Horizonte, ano 2, 2003.

SOARES, Carlos Henrique; BRÊTAS, Ronaldo de Carvalho Dias. Manual Elementar de Processo Civil. Belo Horizonte: Del Rey, 2011. 
STRECK, Lenio Luiz. Hermenêutica, Constituição e Processo, ou de "como discricionariedade não combina com democracia": o contraponto da resposta correta. In: CATTONI DE OLIVEIRA, Marcelo Andrade; MACHADO, Felipe Daniel Amorim (coords.) Constituição e Processo: A contribuição do Processo ao Constitucionalismo Brasileiro. Belo Horizonte: Del Rey, 2009.

THEODORO JUNIOR, Humberto; NUNES, Dierle José; BAHIA, Alexandre. Litigiosidade de Massa e Repercussão Geral no Recurso Extraordinário. In: Revista do Processo. ano 34, n. 77, 2009.

ZAVASCKI, Teori Albino. Processo Coletivo: tutela de direitos coletivos e tutela coletiva de direitos. 2. ed. São Paulo: Revista dos Tribunais, 2007. 